\title{
As múltiplas faces do coordenador pedagógico em institutos privados de idiomas
}

\section{The multiple faces of the pedagogical coordinator in private language institutes}

\author{
Diego Moreno Redondo* \\ dimoreno2@hotmail.com \\ Pontifícia Universidade Católica de São Paulo \\ Adriana Sertóri Sandrin ${ }^{* *}$ \\ adrianascosta@yahoo.com.br \\ Universidade Estadual Paulista Júlio de Mesquita Filho
}

\begin{abstract}
RESUMO: É comum encontrar em institutos privados de idiomas profissionais que atuam como coordenador pedagógico, mas não possuem formação adequada para exercerem tal função. O presente trabalho busca analisar o perfil de cinco coordenadores pedagógicos em seus respectivos institutos de idiomas. Para isso, esta pesquisa realizou um estudo de caso coletivo, aprovado pelo Comitê de Ética da PUC-SP. Os resultados revelaram que esses profissionais realizam funções que não Ihes competem, o que acaba comprometendo o que realmente faz parte do crivo de atividades realizadas pela coordenação de um instituto de ensino. Esta pesquisa apoia-se em autores que tratam do assunto em pauta, tais como Celani, Paiva, Pimenta e Lima, Placco e Almeida, dentre outros.
\end{abstract}

PALAVRAS-CHAVE: Coordenador pedagógico. Ensino-aprendizagem de inglês. Institutos privados de idiomas.

ABSTRACT: In private language institutes, it is common to find professionals who work as pedagogical coordinators but do not have adequate training to carry out this task. This study aims to analyze the profile of five coordinators in their respective language institutes. For this, this study conducted a collective case study, approved by the Ethics Committee from PUC-SP. The results showed that these professionals perform functions that do not concern them, which end up compromising what is really part of the set of activities for coordinating an educational institute. This research is supported by authors who discuss the issue at hand, such as Celani, Paiva, Pimenta \& Lima, Placco \& Almeida, among others.

KEYWORDS: Pedagogical coordinator. English learning and teaching. Private language institutes.

\footnotetext{
Mestre em Linguística Aplicada e Estudos da Linguagem (LAEL) pela Pontifícia Universidade Católica de São Paulo (PUC-SP)

Mestre e aluna de doutorado em Linguística e Língua Portuguesa pela Universidade Estadual Paulista Júlio de Mesquita Filho (UNESP)
} 


\section{Introdução}

A implantação de institutos privados de idiomas no Brasil deve-se a alguns fatores históricos que impulsionaram a grande presença da cultura norte-americana em território brasileiro. Detenhamo-nos a citar apenas alguns acontecimentos que colaboraram para a rápida disseminação de cursos de inglês em órgãos privados.

O Brasil vivia sob o regime de Getúlio Vargas (1930-1945), e foi exatamente na década de 40 que o país sofreu uma grande influência da cultura norteamericana. Essa influência ocorreu porque, durante a Segunda Guerra Mundial, iniciada em 1939, houve uma relação mais formal entre o Brasil e os Estados Unidos.

Ao final da Segunda Guerra Mundial, surge uma demanda por uma língua internacional devido à grande expansão das atividades econômicas e científicas. Nesse contexto, os Estados Unidos passam a dominar o mercado devido ao seu poder econômico. Por essa razão, o inglês passa a ser a língua internacionalmente aceita tanto comercial como academicamente.

Segundo Moura (1993), nosso país, sendo contaminado pela cultura americana e marcado pelo poder dessa potência política, econômica e cultural, também foi influenciado pelos preceitos que regiam os Estados Unidos. Frutos dessa influência são os traços característicos da cultura norte-americana por todo país; palavras provenientes da língua inglesa permeiam o universo brasileiro, nomeando objetos, lojas, comportamentos, alimentos etc. Foi nesse momento que começam a surgir as escolas e os institutos culturais americanos no Brasil, como, por exemplo, o Instituto Brasil-Estados Unidos (IBEU), que, apesar de ter surgido um pouco antes da Guerra, fortaleceu-se ainda mais pós-guerra.

O mercado competitivo entre os institutos privados de idiomas é um fator que colabora com o crescimento maciço de propostas cada vez mais persuasivas por parte desses institutos para conseguirem atrair alunos e se manter no mercado.

Uma pesquisa de Mestrado realizada por Silva (1999), na PUC/SP, cujo objetivo foi analisar os itens lexicais nas propagandas de escolas de idiomas, já revelou que muitos institutos privados de idiomas produzem um discurso retórico ao tentarem atrair novos estudantes. Isso significa a prevalência do aspecto mercadológico sob o que realmente interessa, ou seja, o cuidado com o ensinoaprendizagem da língua alvo e as questões pedagógicas que envolvem o ensinar. 
O número de institutos privados que se dedicam ao ensino de inglês vem aumentando a cada ano e, segundo Moreno (2014), eventos como a Copa do Mundo de 2014 e as Olimpíadas de 2016 contribuem para elevar ainda mais esses números.

A questão da implosão de institutos privados de idiomas no Brasil e o uso da persuasão para atrair novos alunos não são os temas centrais desta pesquisa, porém é imprescindível que os coordenadores desses institutos conheçam bem as metodologias utilizadas, bem como saibam lidar com questões de ordem pedagógica. Esse é o grande problema abordado por este estudo, ou seja, a falta de conhecimento de alguns coordenadores pedagógicos acerca das funções que competem a esse profissional.

Para discutir o perfil de cinco coordenadores pedagógicos de institutos privados de idiomas, esta pesquisa obedece a seguinte estrutura: na primeira seção, descrevemos a metodologia da pesquisa; na segunda seção, apoiamo-nos em alguns teóricos como, por exemplo Almeida Filho (2013), Celani (2010), Placco e Almeida (2011) etc. para definirmos o que é um coordenador pedagógico e quais as suas funções; a seguir, apresentamos a formação dos participantes e suas implicações na carreira desses profissionais; na sequência, discutimos algumas propostas teóricas acerca das atribuições do coordenador pedagógico em consonância com o que a coordenação em análise realiza na prática; por fim, nas considerações finais, tecemos nossa conclusão acerca do tema discutido, baseando-nos nos resultados mencionados ao longo deste trabalho.

\section{Metodologia da pesquisa}

Esta pesquisa foi realizada em um município do interior do Estado de São Paulo. Para compor o estudo, foram selecionados cinco institutos privados de idiomas considerados os melhores da cidade, segundo uma pesquisa de opinião pública realizada por uma revista anual chamada Top of Mind. Portanto, fazem parte deste estudo os cinco coordenadores dos respectivos institutos privados de idiomas destacados pela revista.

Os participantes da pesquisa são nomeados como professor-coordenador 1 (PC-1), professor-coordenador 2 (PC-2), professor-coordenador 3 (PC-3), professorcoordenador 4 (PC-4) e professor-coordenador 5 (PC-5), independentemente do gênero (masculino ou feminino). Todos foram nomeados como professor- 
coordenador porque exercem tanto a função de professor como a de coordenador. Essa nomenclatura foi escolhida para garantir o anonimato dos participantes de acordo com os preceitos éticos que regem esta pesquisa, registrada sob o protocolo de aprovação n 502.754 , expedido pelo Comitê de Ética da PUC-SP.

Para atingir os objetivos da pesquisa, escolhemos, como estratégia de pesquisa, o estudo de caso, de acordo com Stake (1998). Para o autor, o estudo de caso classifica-se em três tipos: o intrínseco, o instrumental e o coletivo. Segundo Stake (1998), o estudo de caso intrínseco está relacionado a um caso em particular, buscando conhecê-lo melhor, não objetivando construir teorias; o estudo de caso instrumental procura conhecer um determinado caso para compreender melhor uma questão ou aprimorar uma teoria; o estudo de caso coletivo tem como objetivo conhecer diferentes casos a fim de ampliar a compreensão de um determinado assunto.

Diante dessa classificação sobre os tipos de estudo de caso, podemos afirmar que este trabalho apoia-se no estudo de caso do tipo coletivo e intrínseco: coletivo porque participam desta pesquisa cinco institutos privados de idiomas, representados por seus professores-coordenadores, em seus reais contextos de trabalho; intrínseco porque a pesquisa pretende conhecer melhor alguns casos em particular, isto é, as múltiplas faces do coordenador pedagógico em institutos privados de idiomas.

Os instrumentos de coleta de dados foram escolhidos de acordo com o contexto da pesquisa, principalmente, respeitando a disponibilidade dos participantes; por isso, só foi possível utilizar o questionário escrito e o e-mail. 0 questionário era composto por vinte e oito questões dissertativas, pois, segundo Nunan (1995), em perguntas abertas, é possível obter dados mais úteis. As primeiras questões abordavam o perfil dos participantes e as demais contemplavam assuntos referentes às atribuições dos coordenadores pedagógicos em seus respectivos ambientes de trabalho. Essa maneira de organizar o questionário, de acordo com Ninin et al (2010), deixa os participantes mais à vontade e confiantes, obtendo informações mais relevantes, optando-se, por isso, por essa ordem estrutural.

No decorrer da coleta, utilizamos outro instrumento: o e-mail dialogado. Atribuímos ao e-mail o adjetivo dialogado porque, ao longo da coleta, foi necessário 
realizar trocas de e-mails para sanar dúvidas oriundas das respostas dos participantes; portanto, esse instrumento funcionou como um diálogo virtual.

Por fim, o questionário e o e-mail dialogado foram suficientes para obtermos os dados necessários para a pesquisa.

\section{Afinal, o que é um coordenador pedagógico?}

No decorrer de nossa experiência como professores, em algumas unidades escolares, sempre nos chamou atenção a função do coordenador pedagógico. Muitas vezes, nos questionávamos sobre o papel desse profissional no ambiente escolar. Essa indagação, cremos que surgiu por nos depararmos com inúmeras situações em que o coordenador executava tarefas que, a nosso ver, não faziam parte do crivo de funções sob responsabilidade desse profissional.

A Secretaria da Educação do Estado de São Paulo (SEE-SP), em Resolução SE-88, de 19-12-2007, considera a coordenação pedagógica um dos pilares estruturais para a melhoria da qualidade de ensino. Por esse motivo, no Art. $2^{\circ}$ desta mesma Resolução, determina que o docente indicado para o exercício da função de professor-coordenador terá as seguintes atribuições:

I - acompanhar e avaliar o ensino e o processo de aprendizagem, bem como os resultados do desempenho dos alunos;

II - atuar no sentido de tornar as ações de coordenação pedagógica espaço coletivo de construção permanente da prática docente;

III - assumir o trabalho de formação continuada, a partir do diagnóstico dos saberes dos professores para garantir situações de estudo e de reflexão sobre a prática pedagógica, estimulando os professores a investirem em seu desenvolvimento profissional;

IV - assegurar a participação ativa de todos os professores do segmento/nível objeto da coordenação, garantindo a realização de um trabalho produtivo e integrador;

$V$ - organizar e selecionar materiais adequados às diferentes situações de ensino e de aprendizagem, para orientar os professores;

VI - conhecer os recentes referenciais teóricos relativos aos processos de ensino e aprendizagem, para orientar os professores;

VII - divulgar práticas inovadoras, incentivando o uso dos recursos tecnológicos disponíveis (SÃO PAULO, 2007).

Embora o excerto supracitado caracterize o papel do coordenador pedagógico em escolas regulares, cremos que a função do coordenador em institutos de idiomas não deva ser diferente, uma vez que é contratado para tratar de questões 
relacionadas ao ensino-aprendizagem e, também, para trabalhar em parceira com os professores.

Ainda sobre a função do professor-coordenador, as pesquisadoras Placco e Almeida (2011) também descrevem o papel que esse profissional deve desempenhar no ambiente escolar:

Como articulador, seu papel principal é oferecer condições para que os professores trabalhem coletivamente as propostas curriculares, em função de sua realidade, o que não é fácil, mas possível;

Como formador, compete-lhe oferecer condições ao professor para que se aprofunde em sua área específica e trabalhe bem com ela;

Como transformador, cabe-lhe o compromisso com o questionamento, ou seja, ajudar o professor a ser reflexivo e crítico em sua prática.

O coordenador pedagógico será, então, aquele que, conhecendo essas propostas, tendo participado de sua elaboração/adaptação às necessidades e objetivos daquela escola, possibilita que "novos significados sejam atribuídos à prática educativa da escola e à prática pedagógica dos professores [...]

Finalmente, como transformador, espera-se sua participação no coletivo da escola como aquele que permite e estimula à pergunta, à dúvida, à criatividade, à inovação. Só assim a escola se instituirá não apenas como espaço de concretização do currículo, mas também como espaço de mudanças curriculares necessárias e desejadas pelos professores, para cumprir seus objetivos educacionais (PLACCO; ALMEIDA, 2011, online).

Conforme as palavras de Placco e Almeida (2011), o coordenador assume a tarefa de mediador, formador, articulador e transformador. Toda essa responsabilidade está em prol de um ensino voltado para a realidade sociocultural a fim de promover um ensino de qualidade.

Uma pesquisa realizada em 2010 e 2011 pela Fundação Victor Civita ${ }^{1}$ em parceira com a Fundação Carlos Chagas $^{2}$ e o Ibope Inteligência ${ }^{3}$, sob a coordenação da Prof. ${ }^{a}$ Dra. Vera Maria Nigro de Souza Placco, professora do programa de pós-graduação em Educação: Psicologia da Educação da PUC-SP, revela que, em muitas esferas educacionais, o coordenador pedagógico assume papéis equivocados. A pesquisa aponta que esses profissionais descuidam-se da

\footnotetext{
${ }^{1}$ Organização paulista, sem fins lucrativos, que tem como objetivo apoiar o trabalho de professores, gestores escolares e formuladores de políticas públicas da Educação Básica Brasileira.

2 É uma entidade fundacional de direito privado, sem fins lucrativos, de utilidade pública, dedicada à avaliação de competências cognitivas e profissionais e à pesquisa na área de Educação.

${ }^{3}$ Empresa especializada em coleta de dados de pesquisas quantitativas e recrutamento de pesquisas qualitativas. Atende aqueles que já dispõem de um planejamento amostral e de questionário e/ou roteiro e têm estrutura própria para análise de resultados.
} 
sua real função. Isso ocorre, segundo Aragão (2011, apud SERPA, 2011), porque eles próprios não conhecem os limites atribuídos à função de coordenador e aceitam as demandas que lhes são dadas. Outro motivo para essa aceitação, segundo Placco e Almeida (2011), tem relação com a falta de uma identidade construída, por isso esse profissional assume funções que acredita fazer parte de sua esfera de competência. Por essa razão, a própria Secretaria da Educação, responsável pela delegação das funções do coordenador ao que concerne o sistema público e privado de ensino do Estado de São Paulo, estipulou os requisitos de habilitação para o professor assumir o cargo de coordenador pedagógico. Essas exigências estão ligadas à formação do profissional que pretende exercer tal função.

No Art. 4 da Resolução SE - 88, de 19-12-2007, a Secretaria da Educação do Estado de São Paulo faz saber que, para se candidatar ao cargo de professorcoordenador, o respectivo docente deve:

I - ser portador do diploma de licenciatura plena;

II - contar, no mínimo, com 3 (três) anos de experiência como docente da rede estadual de ensino;

III - ser docente efetivo classificado na unidade escolar em que pretende ser Professor Coordenador ou ser docente com vínculo garantido em lei, com, no mínimo 10 (dez) aulas atribuídas na unidade escolar em que pretende ser Professor Coordenador (SÃO PAULO, 2007).

É interessante observar os critérios estipulados pela SEE-SP para que um profissional possa assumir a função de coordenador. Essa exigência restringe-se apenas às instituições de ensino que estão sob a vigência legal da SEE-SP. Destaco essa questão legal para mostrar a diferença de critérios exigidos para atuar em escolas regulares e em institutos privados de idiomas. Enquanto em escolas regulares exige-se do professor e do coordenador uma formação específica, em institutos privados de idiomas qualquer profissional, independentemente da formação acadêmica, pode desempenhar as funções de coordenador e de professor.

Diante dessa realidade, fica evidente que a formação do professorcoordenador não é um fator importante nos institutos privados de idiomas, enquanto nas escolas regulares isso é fator primordial e indispensável.

Sobre a questão da formação do professor, a Lei de Diretrizes e Bases da Educação Nacional (LDB-1996) postula, nos Art. 61 e 62, que: 
[...] a formação de profissionais da educação deverá ter como fundamentos a associação entre teorias e práticas, além do aproveitamento da formação e experiências anteriores em instituições de ensino, devendo, ainda, esta formação ocorrer em nível superior, em curso de licenciatura plena, em universidades e institutos superiores de educação (BRASIL, 1996).

A LDB (BRASIL, 1996), responsável por postular os direitos e deveres dos profissionais da educação brasileira, conforme foi constatado no excerto anterior, exige uma formação adequada para que o professor possa assumir as suas funções em seu contexto específico de trabalho. Sendo assim, a formação de professores perante a Lei é um fator importante e deve ser determinante diante de toda e qualquer contratação de professor ou coordenador de ensino em diferentes níveis da educação escolar.

\section{A formação dos participantes da pesquisa e suas implicações na carreira desses profissionais}

Nesta seção, detenhamo-nos à exposição da carreira acadêmica de cada participante desta pesquisa para melhor compreender o status dos profissionais que ocupam o cargo de professor-coordenador nos institutos privados de idiomas que fazem parte deste trabalho.

Após analisar os dados, averiguamos que, dos cinco participantes da pesquisa, apenas três possuem graduação em área específica de ensinoaprendizagem de inglês, sendo que, dos três graduados em Letras, um deles preferiu seguir outros caminhos, graduando-se em Engenharia Civil e Matemática. Esse fato revela que, nos contextos analisados, não é necessário o professor e o coordenador possuírem uma formação acadêmica em Letras ou áreas afins para assumirem ambos os cargos. Para evidenciar ainda mais esse fato, dispomos, a seguir, a formação acadêmica dos participantes: 
Quadro 1: Formação acadêmica dos participantes

\section{Formação acadêmica dos participantes}

PC - 1: Formação técnica em processamento de dados

PC - 2: Graduado em Letras - Inglês, Engenharia e Matemática

PC - 3: Graduado em Letras - Italiano

PC - 4: Graduado em Cinema

PC - 5: Graduado em Letras - Inglês

Fonte: Elaborado pelos autores

Diante dessa informação, confirmamos que os institutos privados de idiomas que compõem esta pesquisa não exigem de professores e coordenadores uma formação acadêmica em área específica: o importante é o profissional dominar a língua a ser ensinada, lembrando que esses profissionais também não possuem pós-graduação em áreas relacionadas ao ensino-aprendizagem de língua estrangeira, tampouco em áreas pedagógicas. Essa questão chamou-nos atenção durante a coleta e análise dos dados, pois mesmo se tratando de uma empresa privada que visa ao ensino-aprendizagem de uma ou mais línguas estrangeiras, a formação acadêmica não deve ser desconsiderada, uma vez que o fato de o professor conhecer os aspectos linguísticos da língua que ensina não indica que ele tenha domínio do funcionamento do ensino-aprendizagem, ou seja, dominar a língua não é suficiente para garantir a aprendizagem. É preciso estar amparado por teorias que explicam como o ensino-aprendizagem ocorre para saber quando e como intervir em diferentes contextos e situações.

Sobre a questão da formação do professor, conforme mencionamos, a LDB (BRASIL, 1996) exige que os profissionais que atuam em escolas públicas e privadas tenham uma formação adequada para conseguirem desempenhar o seu papel de professor ou coordenador. Para isso, deverão receber uma formação em nível superior, em curso de licenciatura plena oferecido por universidades ou institutos superiores de educação.

Além da formação do professor exigida pela LDB (BRASIL, 1996), existe a Resolução SE-88, de 19-12-2007, que estabelece os requisitos para que um docente possa assumir o cargo de coordenador pedagógico em uma escola pública ou privada regida pela SEE-SP. É interessante trazer essa discussão à tona porque isso não ocorre nos institutos privados de idiomas que fazem parte desta pesquisa. 
Os profissionais atuantes no contexto de ensino de inglês dos institutos de idiomas não precisam de uma formação adequada para exercer a função de professor, muito menos de coordenador. Diante disso, fica a indagação: como esses profissionais lidam com questões de ordem pedagógica? Na sequência, trazemos a resposta para essa questão.

A LDB (BRASIL, 1996) deixa claro que a formação do professor deve ter como fundamento básico a associação entre teorias e práticas, por isso, não há como um profissional que não obteve uma formação acadêmica em nível de graduação ou pós-graduação na área específica apropriar-se do conhecimento adquirido durante a formação para promover tal associação. Essa relação entre teoria e prática envolve necessariamente a capacidade do sujeito de questionar as suas e outras práticas à luz das teorias.

Segundo Pimenta e Lima (2002), não é possível desvincular a teoria da prática quando se deixa claro a relação entre ambas:

O papel das teorias é iluminar e oferecer instrumentos e esquemas para análise e investigação que permitam questionar as práticas institucionalizadas e as ações dos sujeitos e, ao mesmo tempo, colocar elas próprias em questionamento, uma vez que as teorias são explicações sempre provisórias da realidade (PIMENTA; LIMA, 2002, p. 43).

Frente a essa problemática, é difícil, no contexto desta pesquisa, os profissionais conseguirem resolver problemas que envolvem suas práticas, não tendo uma formação sólida que sustente o ensino-aprendizagem da língua que ensinam. Um dos motivos para essa dificuldade está na passagem que segue:

além da competência linguístico comunicativa, há também o desenvolvimento dos papéis e das ações que esse profissional irá desempenhar, propiciando a ele os passos iniciais no processo de ensinar e aprender (PAIVA, 1998, p. 66).

Na fala de Paiva (1998), fica evidente que todo profissional atuante no ensino deve ter, no mínimo, uma formação que o gabarite para realizar a sua função na área de formação de outros cidadãos. Em especial, no contexto desta pesquisa, o professor-coordenador é responsável pela formação dos alunos que buscam a aprendizagem de uma língua estrangeira e, principalmente, por estar à frente da orientação e formação dos professores, além de ministrarem aulas. 
De acordo com Leffa (2000), além do papel político e social, o professor deve focar no processo de ensino-aprendizagem e, para lidar com a heterogeneidade de indivíduos que constituem um contexto particular, o docente deve possuir o domínio específico da área, além de dominar, também, as áreas pedagógicas.

O conhecimento pedagógico citado por Leffa (2000) é o que falta ao professor-coordenador que assume uma determinada função sem possuir uma formação adequada para isso. A crítica é: como esses profissionais lidam com o ensino-aprendizagem e com assuntos pedagógicos sem ao menos possuírem uma formação que Ihes dê autonomia para discutir essa temática? Não é possível tratar de aspectos pedagógicos e metodológicos sem um conhecimento satisfatório para refletir sobre os problemas de ensino-aprendizagem que, consequentemente, surgem nesse contexto de trabalho no decorrer do curso e, principalmente, na organização e planejamento do currículo que rege o ensino em institutos privados de idiomas.

Esse fato torna-se problemático não só porque alguns profissionais sem formação adequada atuam nessas áreas, mas, também, porque segundo os professores-coordenadores desta pesquisa, os institutos representados por eles estão preocupados com questões de ordem pedagógica como, por exemplo, planejamento de aulas e cursos, didática, prática docente, ensino-aprendizagem dos alunos, material didático etc.

Essa preocupação fica evidente nos excertos abaixo ${ }^{4}$, extraídos do questionário aplicado aos participantes, no qual uma das questões contemplava a preocupação dos institutos em relação ao ensino de inglês:

PC-1: Tornar possível que o aluno se comunique com base em seu nível de conhecimento. Proporcionando um material de qualidade, treinando professores e coordenadores. Assistindo a escola sempre que necessário.

PC-2: A principal meta do curso é fazer com que o aluno termine o curso em dezoito meses e esteja apto a se comunicar com fluência. Habilitando o aluno com o material testado e aprovado e oferecer as facilidades para aquisição do idioma, através de professores treinados.

\footnotetext{
${ }^{4}$ Esses excertos estão sendo apresentados conforme constam nos questionários respondidos.
} 
PC-3: A principal meta é ensinar inglês através da comunicação. O curso já vem pronto do Departamento de Desenvolvimento de Cursos, com os livros divididos em aulas e atividades propostas com seus procedimentos descritos na apostila do professor.

PC-4: Ensinar com eficácia. Os alunos daqui saem falando inglês e se sentem orgulhosos pela meta alcançada. Através da nossa metodologia desde o livro 1 ao 12 , de fluência.

PC-5: A comunicação eficaz em inglês. Além das aulas seguindo a abordagem comunicativa já descrita anteriormente, incentivamos os alunos a prestarem os exames de proficiência, que são exames extremamente comunicativos assim, além de terem em mãos um certificado de peso se aprovados, os alunos, ao se preparar para esses exames, estarão automaticamente desenvolvendo sua competência comunicativa nas quatro habilidades.

Os excertos supracitados demonstram claramente que, segundo os participantes, há uma preocupação com as questões de ordem pedagógica, ou seja, os institutos estão atentos ao planejamento das aulas, à organização do conteúdo, ao material selecionado, à abordagem escolhida etc. Tudo isso, almejando, como resultado final, a fluência dos alunos na língua alvo. Portanto, para chegar a esse objetivo, de acordo com as falas dos professores-coordenadores, lançam mão de 'treinamento' de professores, materiais de qualidade, metodologia etc. Mais um motivo para que haja pessoas com formação adequada para contribuir nesse aspecto.

A esse respeito, Celani (2010) afirma que, além do domínio da teoria envolvida na situação de ensino-aprendizagem, o professor precisa ter proficiência na língua alvo e conhecer habilidades do ponto de vista pedagógico. Só assim ele conseguirá transpor a mera descrição do sistema em algo que represente o uso desse sistema no universo do aluno, fazendo sentido para ele.

A fala de Celani (2010) leva-nos a concluir que, independentemente do ambiente de formação do aluno, é imprescindível que os profissionais que estão diretamente ligados ao ensino-aprendizagem tenham uma formação adequada para garantir o bom andamento das aulas; ou seja, o professor e o coordenador só conseguem refletir sobre suas práticas e desenvolver as suas funções por meio de uma boa formação pré e em serviço. 
De acordo com Almeida Filho (2013), a falta de uma formação inicial e até mesmo a de uma formação continuada é a causa do despreparo do professor, resultando no desestimulo dos alunos. Isso ocorre porque os professores de diferentes esferas de ensino carregam uma responsabilidade no sentido de não anular, já no início da aprendizagem, a expectativa dos alunos quanto à língua estrangeira.

É fato que alguns institutos oferecem cursos mensalmente, semestralmente ou anualmente para seus professores e coordenadores, porém acreditamos na formação contínua de qualquer profissional da educação em âmbito de graduação e pós-graduação, uma vez que o bom desempenho do professor depende do domínio linguístico da língua estrangeira e do conhecimento pedagógico para realizar a sua prática. Uma formação consistente é o caminho para tornar o professor maduro, crítico e seguro para desenvolver bem o seu papel.

\section{0 professor-coordenador no contexto da pesquisa: o que propõe a teoria acontece na prática?}

Diante da situação em que se encontra, hoje, o coordenador pedagógico, tanto em escolas regulares como em institutos de idiomas, notamos que esse profissional assume uma função multitarefa, ou seja, cabe a ele realizar atividades que não Ihe compete. Nesta seção, detenhamo-nos a traçar o perfil de cada coordenador pedagógico que participa desta pesquisa. Para isso, trazemos novamente a fala de Placco e Almeida (2011) a fim de enfatizar o que é um coordenador pedagógico. Segundo as autoras, esse profissional assume o papel de articulador, transformador e formador, sendo que sua participação no ambiente escolar deve estimular o questionamento, a criatividade e a inovação.

Embora as palavras de Placco e Almeida (2011) caracterizem o papel do coordenador pedagógico em escolas regulares, cremos que a função do coordenador em institutos de idiomas não deva fugir dessa concepção, uma vez que ele é contratado para lidar com questões de ensino-aprendizagem e, também, para trabalhar em conjunto com os professores; caso contrário, não deveria receber essa nomeação.

Conforme a fala de Placco e Almeida (2011), o coordenador assume a tarefa de mediador, formador, articulador e transformador. Toda essa responsabilidade 
está em prol de um ensino voltado para a realidade sociocultural a fim de promover um ensino de qualidade.

Ainda sobre essa questão, Romero (1998) enfatiza que a ação formadora do coordenador significa a possibilidade de provocar um impacto no professor. Essa capacidade de despertar no professor o desejo de mudança, seja pessoal ou profissional, é uma das tarefas do coordenador pedagógico.

De acordo com Placco e Almeida (2011), em escolas regulares, o coordenador pedagógico assume funções que não fazem parte das atribuições desse profissional. Segundo Aragão (2011 apud SERPA, 2011), isso ocorre porque os coordenadores não sabem as fronteiras do seu papel e, por isso, aceitam todas as demandas que lhe são dadas, fazendo coisas demais por não terem a compreensão de que são formadores.

A realidade dos institutos privados de idiomas não é algo tão distante da situação encontrada nas escolas regulares. Durante nossa pesquisa, percebemos que alguns professores-coordenadores que participam deste estudo também realizam funções que não deveriam ser atribuídas ao coordenador.

Essa revelação veio à tona a partir de uma descrição das funções realizadas no contexto de trabalho dos professores-coordenadores, como parte do questionário investigativo aplicado a todos eles. A partir das respostas de cada um, constatamos que eles também realizavam tarefas que não eram da responsabilidade deles.

Nos trechos que seguem, os professores-coordenadores descrevem a rotina realizada por eles no ambiente de trabalho:

PC-1: Coordenar os professores, atribuir turmas, organizar horários, selecionar e treinar professores, contatar os pais, nivelar os alunos, checar as faltas dos alunos.

PC-2: Tenho atividades diárias, semanais, quinzenais e mensais. Basicamente, a rotina é lembrar os alunos das aulas, quais as tarefas que deve realizar e preparar, cadastrar as faltas, as lições que os alunos fizeram ou deixaram de fazer, controlar o nível de inglês dos professores, inter-relação pessoal com os professores e alunos, interagir com outras unidades para reposição dos alunos e participar de reciclagem de curso de coordenador semanalmente, etc. 
PC-3: Como coordenador sou responsável pela montagem das turmas, distribuição de horas entre os professores, entrevista inicial da seleção de professores e acompanhamento do treinamento feito pela unidade central do grupo. Em relação a alunos, faço a entrevista de classificação para colocar o aluno na melhor turma de acordo com seu conhecimento prévio e acompanhamento de desempenho através da observação de aulas, análise de provas e longas conversas com professores sobre como ajudar aqueles que precisam de um "extra".

PC-4: Auxiliar, coordenar e checar os professores quanto à metodologia. Atendimento direto a alunos. Providenciar reforço e material extra quando necessário. Sou responsável pelo bom andamento de aulas, providenciar substituições. Checo o geral da escola, desde as instalações a satisfação dos alunos. Confiro a frequência dos alunos, atender pais, fazer relatórios, dentre outras.

PC-5: Sou responsável pela seleção e escolha de materiais didáticos (coursebooks), preparação de testes/exames escritos e orais, treinamento de professores (observação de aulas, feedback, cursos de treinamento) e também atendo alunos/pais de alunos que querem informação sobre nossos cursos ou orientação de estudo.

Os excertos sobre a rotina dos professores-coordenadores mostram claramente que o PC-1, PC-2, PC-3 e PC-4 realizam tarefas que não cabem a eles executarem. O PC-1 é responsável por organizar os horários das aulas, checar as faltas dos alunos e contatar os pais caso haja necessidade; já o PC-2 é responsável por lembrar os alunos das aulas e também lembrá-los das atividades que precisam realizar ou não realizaram, além de cadastrar faltas; o PC-3 monta as turmas, organiza os horários e os distribui entre os professores; o PC-4 também exerce funções equivocadas, dentre elas estão: checar faltas dos alunos, providenciar substituição, fazer relatórios etc., porém o mais grave dentre elas é ter que checar as instalações da escola. Todas essas funções poderiam ser realizadas por uma secretária, por exemplo, pois não é função do coordenador realizar esse tipo de tarefa. Está muito claro que todos esses professores-coordenadores exercem funções que não são da responsabilidade desses profissionais. Esse fato contribui 
para tornar a profissão de coordenador um cargo banalizado devido a não compreensão das atribuições pertinentes ao coordenador pedagógico.

De fato, tanto a pesquisa já realizada pela Fundação Victor Civita, como os exemplos já mencionados mostram a dificuldade de se delimitar o papel do coordenador pedagógico no cenário educacional brasileiro, seja em escola regular ou em instituto privado de idiomas. Em decorrência da falta de identidade do coordenador, esse profissional acaba recebendo uma sobrecarga de trabalho que foge à sua competência, geralmente, por falta de conhecimento do próprio coordenador ou do gestor responsável pela unidade de ensino.

Em institutos privados de idiomas, a situação é ainda mais alarmante, pois além de exercerem diversas funções, esse profissional, na maioria das vezes, não possui uma formação adequada para exercer o cargo de coordenador pedagógico. Ou seja, em escolas regulares, geralmente, o coordenador possui uma formação adequada, porém não dá conta de realizar sua devida função por estar sobrecarregado, já nos institutos de idiomas, encontra-se a junção da falta de formação específica e acúmulo de tarefas.

Essa sobrecarga de funções acaba prejudicando o andamento do trabalho do coordenador e o distanciando de sua real tarefa dentro do ambiente de ensino. Sobre essa questão, Placco e Souza (2012) enfatizam:

O CP acaba por se apropriar de funções administrativas e organizativas que não são privativas de sua função. Esse fato traz consequências que em muito prejudicam a função do $\mathrm{CP}$, tendo em vista o caráter pedagógico que deve ser central em suas ações, já que os problemas administrativos e organizacionais tendem a tomar grande parte de seu tempo. Desse modo, o fato de estar mais envolvido com o administrativo que com o pedagógico impede que o $\mathrm{CP}$ assuma seu papel de mediador na escola, isto é, que tome como ponto de partida e de chegada de suas ações o pedagógico, uma vez que o objetivo maior de sua ação deve ser a melhoria constante e permanente da aprendizagem dos alunos (PLACCO; SOUZA, 2012, p. 11).

Todos os professores-coordenadores já apresentados assumem um papel importante nos contextos de ensino os quais coordenam, porém, em comparação com os demais professores-coordenadores, percebe-se que a função do PC-5 está limitada à área pedagógica, pois ele é responsável somente por selecionar e escolher os materiais utilizados pelos alunos e promover cursos de formação para 
os professores. Os outros professores-coordenadores também realizam atividades na área pedagógica, todavia são responsáveis por outras funções que não deveriam ser atribuídas a eles. Além de todas essas atividades, é importante ressaltar que todos os professores-coordenadores deste estudo foram assim nomeados porque exercem a função de coordenadores e, também, atuam como professores. Isso mostra que a situação é ainda mais preocupante, pois a rotina de um professor demanda muito tempo, por isso, atrelada às demais funções atribuídas aos coordenadores, que tempo lhes resta para se dedicarem à coordenação pedagógica e realizarem, de fato, a função que lhes cabem? Com tantos afazeres, o tempo torna-se escasso e insuficiente para realizar, com responsabilidade e maestria, o papel que o cargo exige no contexto de ensino.

No contexto específico do ensino de línguas, especialmente os analisados neste trabalho, parece não haver uma grande preocupação com essa questão, uma vez que os profissionais contratados para o cargo de coordenador geralmente não possuem uma formação acadêmica em Letras, Pedagogia ou áreas afins para tal função. Isso ficou claro no momento em que apresentamos a formação acadêmica dos participantes desta pesquisa, no Quadro 1, comprovando que somente os PC-2, PC-3 e PC-5 apresentam uma formação em área específica e, mesmo assim, o PC2 seguiu outros caminhos como Engenharia Civil e Matemática por estar descontente com a atuação na área.

No decorrer da análise, pudemos constatar que, em todos esses institutos de idiomas, a formação acadêmica não é um critério para a contratação de professores e coordenadores. O único requisito exigido é a fluência na língua inglesa.

Os trechos a seguir mostram a opinião dos professores-coordenadores sobre os motivos que levaram à contratação de cada um deles para assumirem a coordenação de um instituto de ensino de línguas:

PC-1: Pelo meu comprometimento e seriedade com o ensino.

PC-2: Devido as minhas experiências anteriores de professor e discente.

PC-3: Sou coordenador desde 2003 e a escolha foi por eu ter uma visão de todas as facetas do negócio, conhecer profundamente o curso oferecido pela escola e senioridade.

PC-4: Eu era professor de inglês aqui e quando surgiu a vaga me candidatei. Por que tenho iniciativa e gosto de liderança. 
PC-5: Vários motivos podem ter contribuído para que eu tenha sido escolhido $\mathrm{p} / \mathrm{o}$ cargo: minha dedicação e paixão pela escola, e também o fato de 0 departamento acadêmico estar em franco crescimento nessa época.

É possível observar que todos os professores-coordenadores acreditam terem sido contratados por méritos não relacionados à formação especifica na área de ensino de línguas como, por exemplo, experiência como professor, dedicação, liderança, gosto pela profissão etc. A fala de todos eles revela que, em nenhum momento, foi levado em consideração a formação acadêmica de cada um, ou seja, os proprietários dos institutos ou os diretores não exigem uma formação adequada para se assumir o cargo de coordenador. Por esse motivo, mesmo não tendo uma formação específica na área, alguns desses profissionais foram contratados. Isso mostra a não importância dada pelos institutos de idiomas em relação à formação acadêmica ou continuada dos profissionais que são contratados para assumirem um papel importante dentro do contexto de ensino de línguas. A descrição do perfil de cada professor-coordenador e suas respectivas formações revela claramente que o PC-1 e PC-4 foram contratados mesmo não sendo habilitados na área e, caso o PC2 e o PC-3 não fossem formados na área, bastaria serem fluentes na língua, e não haveria problema quanto à contratação. Em relação ao PC-5, houve a exigência do certificado de proficiência em língua estrangeira, além de outros cursos, porém, quanto à formação em Letras ou área pedagógica, não houve obrigatoriedade.

Diante dessa situação, pode-se concluir que os professores-coordenadores dos institutos privados de idiomas analisados nesta pesquisa foram contratados porque cada um (a saber: gosta da profissão, tem liderança, conhece o negócio, a área estava em crescimento), tem experiência como professor, além de outros motivos, uma vez que todos eles não foram admitidos tendo como critério predominante a formação acadêmica específica na área, seja em nível de graduação ou pós-graduação. É difícil apontarmos a provável razão dessa desvalorização por parte dos institutos privados de idiomas, contudo é permitido levantar hipóteses das possíveis causas. Uma delas seria a tentativa de reduzir gastos, não admitindo novos funcionários; a outra estaria relacionada à falta de conhecimento sobre as questões ligadas ao ensino, fazendo com que os responsáveis por esses institutos vejam como uma alternativa mais cômoda a 
distribuição das tarefas entre os profissionais que já atuam no instituto, independentemente do cargo que assumem.

Os fatores que levaram os responsáveis pela contratação de profissionais de institutos de idiomas a assumirem essa posição não são os pontos principais nesta discussão. O que se torna lamentável é o descaso com a profissão de professor e coordenador, já que qualquer profissional fluente em língua estrangeira poderá assumir essas funções dentro de um desses institutos de idiomas, mesmo sendo graduado ou pós-graduado em uma área alheia à docência ou à coordenação. Isso não acontece na maioria das outras áreas profissionais, isto é, um professor ou coordenador não pode, por exemplo, atuar como advogado, engenheiro, enfermeiro etc. sem uma formação adequada para exercer tal profissão, pois toda carreira profissional possui suas especificidades e, em vista disso, os cursos de nível técnico ou superior são organizados e estruturados com o intuito de oferecer conhecimento suficiente para que todo profissional conclua a sua formação e esteja apto a assumir a função a qual lhe foi concedido o grau. Por isso, cada profissional deve atuar em sua área de formação; caso contrário, não há uma valorização do profissional e o serviço prestado dificilmente será de qualidade.

Portanto, somando a não formação adequada e as diversas funções atribuídas ao coordenador pedagógico no contexto dos institutos de idiomas analisados durante toda esta pesquisa, obtêm-se como resultado, provavelmente, a dificuldade em lidar com problemas de ensino-aprendizagem e, consequentemente, o comprometimento das questões pedagógicas.

\section{Considerações finais}

Este trabalho proporcionou uma viagem pelo contexto dos institutos privados de idiomas, mais precisamente, pelo universo do professor-coordenador.

Os resultados da pesquisa revelaram dois pontos que merecem atenção: o primeiro está ligado à formação dos profissionais contratados para atuarem como coordenador pedagógico. Está claro que os institutos analisados neste trabalho não se preocupam com a formação dos profissionais que neles atuam, pois embora três professores-coordenadores tenham formação na área de Letras, não haveria problema para admiti-los mesmo sem formação adequada: o exigido é apenas o domínio da língua estrangeira ensinada pelo instituto. Esse fato comprova o descaso 
com a formação de profissionais que atuam nesses institutos de idiomas. O segundo ponto importante é o desconhecimento da diretoria dos institutos e do próprio professor-coordenador sobre o crivo de funções que ele deve realizar. As falas dos participantes revelam que, com exceção do PC-5, todos os demais realizam tarefas que não fazem parte das atribuições de um coordenador. Esse problema evidencia a falta de identidade do coordenador pedagógico, conforme já afirmou Placco e Almeida (2011). Isso nos leva a crer que se desconhece a verdadeira função desse profissional ou é mais viável transformá-lo em um funcionário multifacetado para evitar a contratação de novos servidores.

Diante desses problemas, é possível dizer que, muitas vezes, os coordenadores pedagógicos assumem tarefas que não lhes competem, porque precisam do trabalho ou não conhecem a função de um coordenador. Com isso, o aspecto pedagógico e de ensino-aprendizagem são comprometidos devido à falta de formação atrelada à sobrecarga de trabalho.

Por fim, após esta discussão acerca da formação e do papel do professorcoordenador em contextos de ensino de línguas, esperamos que este artigo desperte um olhar mais atento ao ensino oferecido em institutos privados de idiomas, pois os coordenadores são responsáveis pela formação dos professores, além de responderem pelos problemas de ordem pedagógica que surgem em qualquer ambiente de ensino; ou seja, para um ensino sério e de qualidade, é imprescindível que tanto os professores como os coordenadores conheçam as suas atribuições e saibam executá-las com responsabilidade.

\section{Referências}

ALMEIDA FILHO, J. C. P. de. Dimensões comunicativas no ensino de línguas. 7. ed. Campinas, SP: Pontes, 2013.

BRASIL. Senado Federal. Lei de Diretrizes e Bases da Educação Nacional: $n^{\circ}$ 9.394, Brasília, DF, 20 de dezembro de 1996. Brasília.

CELANI, M. A. A. Reflexões e ações (trans)formadoras no ensino-aprendizagem de inglês. Campinas, SP: Mercado de Letras, 2010.

LEFFA, V. J. O ensino de línguas estrangeiras no contexto nacional. Contexturas: ensino crítico de língua inglesa, n. 4, p. 13-24, 2000. Disponível em: <http://pt.scribd. com/doc/167910345/Contexturas-4>. Acesso em: 31 jul. 2014. 
MORENO, A. C. Brasil perde oportunidades por falta de domínio do inglês. Disponível em: <http://g1.globo.com/educacao/noticia/html>. Acesso em: 02 mar. 2014

MOURA, G. Tio Sam chega ao Brasil: a penetração cultural americana. São Paulo: Editora Brasiliense, 1993.

NININ, M. O. G. et al. Questionários: instrumentos de reflexão em pesquisas na Linguística Aplicada. Contexturas: ensino crítico de língua inglesa, v. 8, p. 91-113, 2010. Disponível em: <http://pt.scribd.com/doc/167925163/Contexturas-8>. Acesso em: 31 jul. 2014.

NUNAN, D. Language teaching methodology: a textbook for teachers.Upper Saddle River, NJ: Prentice Hall, 1995.

PAIVA, V. L. M. A LDB e a legislação vigente sobre o ensino e a formação de professor de língua inglesa. In: STEVENS, C. M. T; CUNHA, M. J. Caminhos e colheitas: ensino e pesquisa na área de inglês no Brasil. Brasília: UnB, 1998, p. 5384.

PIMENTA, S. G.; LIMA, M. S. L. Estágio e docência. 2. ed. São Paulo: Cortez, 2002.

PLACCO, V. M. N. de S.; ALMEIDA, L. R. de. O papel do coordenador pedagógico. Revista Educação, 2011. Disponível em: <http://revistaeducacao.uol.com.br/textos>. Acesso em: 31 jul. 2014.

(Orgs.). O Coordenador pedagógico e os desafios da educação. 5. ed. São Paulo: Edições Loyola, 2012.

PLACCO, V. M. N.; SOUZA, V. L. T de. O trabalho do coordenador pedagógico na visão de professores e diretores: contribuições à compreensão de sua identidade profissional. In: PLACCO, V. M. N; ALMEIDA, L. R. (Orgs.) O Coordenador pedagógico: provocações e possibilidades de atuação. 2.ed. São Paulo: Edições Loyola, 2012.

ROMERO, T. R. de S. A interação coordenador e professor. um processo colaborativo? 1998. 199 f. Tese (Doutorado em Linguística Aplicada e Estudos da Linguagem) - Pontifícia Universidade Católica de São Paulo, São Paulo, 1998.

SÃO PAULO (Estado). Secretaria da Educação do Estado de São Paulo. Resolução SE-88: dispõe sobre a função gratificada de professor coordenador, São Paulo, 19 de dezembro de 2007.

SERPA, D. As faces equivocadas. Revista Gestão Escolar, 2011. Disponível em: $<$ http://gestaoescolar.org.br/comunidade/6-papeis-equivocados-coordenadorpedagogico-634935.shtml>. Acesso em: 31 jul. 2014.

SILVA, M. S. F. da. Análise lexical de folhetos de propagandas de Escolas de Línguas e as representações de ensino. 1999. 175 f. Dissertação (Mestrado em 
$\mathbb{B}_{\text {disse }} \mathcal{A}$

Linguística Aplicada e Estudos da Linguagem) - Pontifícia Universidade Católica de São Paulo, São Paulo, 1999.

STAKE R. E. Case Studies. In: DENZIN, N. K.; LINCOLN, Y. S. (Orgs.). Strategies of qualitative inquiry. Londres: SAGE Publications, 1998, p. 86-109.

Recebido em 15/06/2016

Aprovado em 27/06/2016 